\title{
Discursos europeos del siglo XVII sobre la apostasía y la conversión al Islam: Un texto del cautivo francés Germain Moüette sobre Bernard Bausset y los catorce leones del sultán Mulay Ismail de Marruecos
}

\author{
Araceli GonZÁlez VÁZQUEZ \\ Laboratoire d'Anthropologie Sociale, Collège de France (París) \\ lacuerre@gmail.com
}

Recibido: 26 de julio de 2012

Aceptado: 9 de octubre de 2014

\section{RESUMEN}

La historia del cautivo francés Bernard Bausset, que sobrevive tras ser arrojado a un foso con catorce leones hambrientos por parte del sultán de Marruecos Mulay Ismail, forma parte de la Relation de captivité de Germain Moüette, una obra editada en París en 1683. Este relato nos permite explorar la instrumentalización religiosa y política de la memoria traumática de los cautivos europeos en el norte de África. En particular, analizamos la construcción de la figura del mártir, los discursos sobre la conversión al Islam y la apostasía del Cristianismo, y la construcción de la imagen de uno de los sultanes más importantes de la historia de Marruecos, el citado Mulay Ismail.

Palabras clave: cautiverio, Marruecos, Islam, conversión, apostasía, Mulay Ismail, Germain Moüette.

\section{XVII ${ }^{\text {th }}$ Century European Discourses on Apostasy and Conversion to Islam: A Text by French Captive Germain Moüette on Bernard Bausset and the Sultan of Morocco Mulay Ismail's Fourteen Lions}

\begin{abstract}
The story of the French captive Bernard Bausset, who survives being thrown into a den with fourteen hungry lions, as ordered by Mulay Ismail, the sultan of Morocco, is part of Germain Moüette' s Relation de captivité, a book published in Paris in 1683. This story allows us to explore the religious and political instrumentalisation of the traumatic memory of European captives in North Africa. In particular, we will analise the construction of the martyr's figure, the ideas on conversion to Islam and apostasy from Christianity, and the construction of the image of one of the most important sultans in Morocco's history, the aforementioned Mulay Ismail.
\end{abstract}

Key words: Captivity, Morocco, Islam, Conversion, Apostasy, Mulay Ismail, Germain Moüette. 
La historia que centrará nuestra atención en este artículo, la del cautivo Bernard Bausset, forma parte de un relato de cautiverio francés del siglo XVII frecuentemente citado por los historiadores que estudian el Mediterráneo en la Edad Moderna, particularmente por quienes abordan el tema del corso y de la esclavitud, y analizan las relaciones entre los reinos cristianos y musulmanes de Europa y del norte de África. Este relato data de finales del siglo XVII, se titula Relation de la captivité du Sieur Moüette dans les royaumes de Fez et de Maroc ${ }^{1}$, y fue publicado por primera vez en 1683 en París. El autor de la memoria autobiográfica es Germain Moüette, francés natural de la villa de Bonnelles, en la diócesis de Chartres², que había pasado once años de su vida cautivo en Marruecos (1670-1681), en los tiempos de los sultanes alauíes Mulay Rashid (1666-1672) y Mulay Ismail (1672-1727). La obra de Moüette es además conocida porque contiene el que al parecer es el primer diccionario europeo francés-árabe marroquí, el llamado Dictionaire François-Arabesque, último capítulo de la Relation, que contiene ochocientos cincuenta y cuatro términos ${ }^{3}$.

La historia del cautivo Bernard Bausset es el capítulo séptimo de la obra de Moüette, y se titula L'histoire de Bernard Bausset, qui fut exposé entre quatorze lions affamez, le 15 février $1681^{4}$. Germain Moüette escribe al comienzo de su relato que el cautivo Bausset era el guardián de la vestimenta y las armas de los pajes, que tenía encargado el cuidado de los almacenes reales, y que enseñaba la lengua española a los hijos del sultán Mulay Ismail ${ }^{5}$. Esto último tiene interés, ya que Moüette ha sido muy citado por varios historiadores (entre otros, por Fernand Braudel) ${ }^{6}$, donde dice que el español se hablaba tanto como el árabe en el Marruecos de la época: "Les Maures en $s^{\prime} y$ retirant [au Maroc], $y$ portèrent la langue espagnole qui y est encore aussi commune aujourd'hui que l'arabe" 7 . La afirmación de Moüette pudo haber pretendido subrayar la importancia del español como lengua franca. De hecho, no eran pocos

1 En realidad, la obra tiene un título más extenso, como es común en la época. Este título es el de Relation de la captivité du Sieur Moüette dans les royaumes de Fez et de Maroc, où il a demeuré pendant onze ans. Où l'on void les persecutions qui y font arrivées aux chrétiens captifs, fous les regnes de Mouley Archy, et de Mouley Seméin, son successeur regnant aujourd'huy et les travaux ordinaires ausquels on les occupe. Avec un traité de commerce et de la maniere que les negotians s'y doivent comporter, ensemble les termes principaux de la langue qui est la plus en usage dans le país.

2 Nordman, D.: "Moüette, Germain", en Poulllon, F. (ed.): Dictionnaire des orientalistes de langue française, París, Karthala, 2008, pp. 710-711. Más información sobre el cautivo, véase: TuRBET-DELOF, G. y Ben Mansour, H.: “Germain Moüette, historien des premiers chérifs alaouites", Revue de l'Histoire du Maghreb, 5 (1976), 102 y ss.

3 Hemos publicado un estudio de este Dictionaire François-Arabesque en: GonzÁlez VÁzQuEz, A.: "El árabe marroquí visto por un cautivo francés del siglo XVII: Estudio histórico, social y cultural del Dictionaire françois-arabesque de Germain Moüette", Miscelánea de Estudios Árabes y Hebraicos, Sección Árabe-Islam, 63 (2014), pp. 65-90.

4 La historia se desarrolla entre las páginas 93 y 100 de la obra. La relación de cautiverio de Germain Moüette es una obra extensa que cuenta con más de trescientas cincuenta páginas en la edición que manejamos - una copia digital de la original de 1683 editada en París. La copia digital de la obra de Moüette se puede obtener fácilmente de Google Books (http://books.google.es). Es la digitalización de un ejemplar que se conserva en la Universidad de Lausana, en Suiza.

5 Moüette, G.: Relation de la captivité du Sieur Moüette, París, Jean Cochart, 1683, p. 93.

6 Braudel, F.: "Conflits et refus de civilisation: espagnols et morisques au XVIe siècle", Annales. Économies, Sociétés, Civilisations, 4 (1947), pp. 397-410. Maziane, L.: Salé et ses corsaires, 1666-1727, Caen, Presses Universitaires de Caen, 2007.

7 MOÜETTE, op. cit. (nota 5), preface. 
los cautivos europeos que aprendían español durante su estancia en Marruecos o en Argel, entre ellos el propio autor ${ }^{8}$. La labor docente del cautivo Bausset con los hijos del sultán incide en la misma idea ${ }^{9}$.

Moüette ofrece algunos datos más sobre Bausset: que tenía veinticinco años, que pertenecía a la familia de los Bausset, antiguos cónsules de Marsella, que era natural de la localidad de Aubagne (Aubaigne en el original), en la región de Provenza, y que el sultán le había tomado cierto afecto. Esta habría sido una de las razones que había movido a Mulay Ismail a intentar convertirle al Islam. La otra es que el sultán pretendía "ascenderle" (l'élever plus haut) y la religión cristiana constituía un obstáculo para ello ${ }^{10}$. En relación con esta cuestión tenemos que apuntar que en muchos otros relatos, la conversión al Islam se presenta como una vía de ascenso social: podía garantizar un mejor trato y podía favorecer la liberación del esclavo. Moüette nos indica que Bausset se había resistido a renegar de su fe cristiana con tanta determinación que había despertado las iras de su dueño. Así habían comenzado las torturas, y así se habría desencadenado el principal castigo que sufrirá Bausset por parte del gobernante, el "cruel martirio" al que hace referencia la obra ${ }^{11}$ : Bausset será arrojado a un foso con catorce leones hambrientos, e inexplicablemente (y aquí se opera el "milagro"), los leones permanecerán mansos y no le atacarán. Bausset salvará la vida, y ulteriormente obtendrá la libertad de parte de un sultán fascinado por el suceso.

La Relación de Moüette sitúa la historia de Bausset en el reinado de Mulay Ismail, un período importante dentro de la historia de Marruecos y del Mediterráneo si tenemos en cuenta varias cuestiones. Por un lado, que este sultán llegó a monopolizar el comercio de esclavos en la zona, y que renunció a negociar en materia de redenciones, con lo que durante su "reinado" llegaron a trabajar en sus palacios y obras públicas más de dos mil europeos ${ }^{12}$. Por otro lado, que Mulay Ismail recuperó La Mamora ${ }^{13} \mathrm{y}$ Larache de manos españolas, y Tánger de manos inglesas, que asedió Ceuta y otros presidios, y que formó una guardia negra -denominada abid al-bukhari y compuesta por marroquíes descendientes de esclavos negros y por esclavos negros ${ }^{14}-$, que fortaleció su capacidad administrativa y su dominio de las cabilas del país. Esta es, por lo tanto, una época un tanto convulsa, una época en la que un sultán de Berbería consigue frenar con éxito el avance ibérico sobre el norte de África.

\footnotetext{
8 Véase Dakhlia, J.: Lingua franca. Histoire d'une langue métisse en Méditerranée, Arles, Actes Sud, 2008 .

9 No obstante, esta lengua española podría comprender también el español de los moriscos (que es a lo que apunta Moüette cuando habla de los "moros” retirados de España a Marruecos) y el judeo-español o haquetía, ya que Moüette, cuando hable de su patrona, la esposa de su dueño judío, dirá que hablaba muy bien "el español", y cabe pensar que se trataba de judíos sefardíes [MOÜETTE, op. cit. (nota 5), p. 27].

10 MoüetTe, op. cit. (nota 5), pp. 93-94.

11 MoüEtTe, op. cit. (nota 5), pp. 94-95.

12 Martínez Torres, J. A.: "El alimento necesario para ir más allá": Fernand Braudel, el mundo turcoberberisco y los estudios sobre cautivos y renegados (siglo XVI y XVII)”, Hispania Sacra, 53 (2001), pp. 761-785, p. 775.

13 La Mamora es la actual ciudad de Mehdia, en la desembocadura del río Sebú.

14 Véase, Meyers, A. R.: "Class, ethnicity and slavery: The origins of the Moroccan 'Abid", The International Journal of African Historical Studies, 10, 3 (1977), pp. 427-442. MEYERs, A. R.: "Slave soldiers and state politics in early 'alawi Morocco, 1668-1727", The International Journal of African Historical Studies, 16,1 (1983), pp. 39-48.
} 
Los relatos de cautiverio y redención nos permiten explorar qué tipo de ideas y qué visiones de las sociedades de mayoría musulmana del norte de África circulaban en Europa en esta época. La difusión de estos textos, como veremos más adelante, será bastante amplia, y en cierta manera es lógico que exista un interés por ellos entre los lectores europeos del momento, ya que se supone que ofrecen información de primera mano sobre países con los que los reinos cristianos del norte del Mediterráneo mantienen un conflicto persistente. Los relatos de cautiverio y redención pueden ser leídos como discursos de producción europea sobre el Islam y las sociedades del norte de África, particularmente sobre un Otro con el que se mantiene un latente conflicto político, económico y territorial. La religión es un elemento de central relevancia dentro de tales discursos, de modo que las notas sobre la resistencia en la fe cristiana de los cautivos europeos son siempre numerosas en este tipo de relatos.

Por lo general, estos textos representan como bárbaras e incivilizadas a las sociedades del norte de África, fundamental pero no únicamente para justificar la beligerancia contra ellas, y también, en el caso de España y Portugal, para legitimar y justificar la ocupación de su territorio. Es una literatura que tiene un doble fin político y religioso, y que da lugar a un interesante fenómeno de difusión de las concepciones de la identidad nacional, de la identidad religiosa y de la identidad cultural. Las órdenes redentoras, la Orden de la Santísima Trinidad, y la Orden de Nuestra Señora de la Merced, necesitan las limosnas de los fieles europeos para organizar sus expediciones de rescate ${ }^{15}$, y estos relatos que describen las penurias de los cautivos mueven fácilmente a la compasión y a la caridad. La redención de cautivos también forma parte de las agendas políticas de los gobernantes cristianos de la orilla norte del Mediterráneo, y por lo tanto los relatos de redención difunden las acciones de "recuperación de súbditos" y "recuperación de fieles" que ejercen principalmente las órdenes redentoras al amparo de las monarquías católicas europeas, particularmente Francia y España. Y esta recuperación no sólo se refiere al traslado de los cautivos del norte de África a Europa, sino a una exaltación de las conciencias, y a un énfasis en las adhesiones religiosas y culturales. En otro orden de cosas, este género sitúa las memorias traumáticas personales de los cautivos y la elaboración de relatos de tipo autobiográfico al servicio del expansionismo y del imperialismo.

En este artículo, a través del breve texto de Moüette sobre Bausset y Mulay Ismail, procuraremos analizar cuáles son los recursos ideológicos y narrativos concretos que se movilizan para la consecución de los mencionados fines.

\section{GERMAIN MOÜETTE Y SU RELATION DE CAPTIVITÉ}

Germain Moüette nació en 1651 y muy probablemente murió a comienzos de la década de los noventa del siglo, más o menos un decenio después de que se produjera su

\footnotetext{
15 Sobre el rescate de cautivos, véase especialmente KAISER, W.: Le commerce des captifs: les intermédiares dans l'échange et le rachat des prisonniers en Méditerranée, XVe-XVIIIe siècle, Roma, École Française de Rome, 2008, y VInCENT, B.: Procédures et réseaux de rachats de captifs dans l'Espagne des XVIe-XVIIe siècles, Roma, École Française de Rome, 2008.
} 
rescate por parte de religiosos de la Orden de la Merced ${ }^{16}$. La obra sobre la que estamos escribiendo nos ofrece algunos datos sobre él. Había salido de París el último día de julio de 1670 en compañía de un primo suyo, llamado Claude Loyer La Garde, y un amigo de ambos. La idea de los tres hombres -Moüette tenía entonces diecinueve años- era la de embarcarse hacia las Indias Occidentales, cosa que finalmente harían en el puerto de Dieppe, en una fragata llamada La Royale, el día 16 de septiembre del mismo año ${ }^{17}$. Dieppe, situado en las costas de Normandía, era uno de los puertos que más convenían a los habitantes de París, y a lo largo de la Edad Moderna servirá de refugio a los corsarios que operan en el Canal de La Mancha y que atacan a las flotas inglesas, portuguesas y españolas ${ }^{18}$. La presencia de corsarios otomanos tampoco era extraña en estas aguas, ya que el corso se había ido extendiendo por el Atlántico. La fragata en la que se había embarcado Moüette, que navegaba rumbo a las Antillas, fue atacada por unos corsarios que fingían ser turcos procedentes de Argel, que apresaron a toda la tripulación y la condujeron al puerto de Salé, en la costa atlántica del norte de África. Salé era en la época uno de los puertos más relevantes del área, y un concurrido mercado de esclavos europeos y africanos ${ }^{19}$.

Moüette llegó a Salé el 25 de octubre de 1670, y fue vendido el día de Todos los Santos a cuatro dueños por trescientos sesenta escudos: la mitad de Moüette le pertenecía al Alcayde Hamet Ben-Yeucourt, y la otra mitad a tres patrones: Mahamet le Maraxchy, el guardián real de los pesos; Mahamet Liébus, mercader de lana y de aceite; y Rabby Yemin, un judío ${ }^{20}$. En Marruecos, Moüette desempeñó diversos trabajos, parte de ellos en las obras del palacio de Mulay Ismail en Mequinez y en las obras de canalización de la ciudad de Alcazarquivir ${ }^{21}$. En el transcurso de la misión redentora de los padres de la Merced, Moüette tuvo la oportunidad de declarar que llevaba once años cautivo y que era pobre. Su obra refiere su liberación de la siguiente manera: Moüette se postró a los pies del sultán, y Mulay Ismail mandó preguntar cuál era su ocupación. Le dijeron que molía colores para los que trabajaban el yeso. Entonces el sultán dijo: "En once años, ¿No ha podido aprender algún otro oficio? Es una bestia, uno nuevo que vendrá dentro de cuatro días hará tanto, marcha, ve en libertad"22. Moüette fue rescatado en 1681 y partió de Mequinez hacia París el 25 de febrero de ese año ${ }^{23}$.

Germain Moüette escribió dos obras a partir de su cautiverio en Marruecos: una es la que nos concierne ${ }^{24}$, y la otra se titula Histoire des conquetes de Mouley Archy,

16 Nordman, op. cit. (nota 2), p. 710.

17 MoüETTE, op. cit. (nota 5), preface.

18 Villiers, P.: Les corsaires des origines au traité de París du 16 avril 1856, París, Gisserot, 2007.

19 Véase, Maziane, op. cit.

20 MoüEtTe, op. cit. (nota 5), p. 23.

21 Ibidem, p. 81 .

22 Ibidem, p. 143. Todas las traducciones del francés al castellano de fragmentos de la obra de Moüette que aparezcan en lo sucesivo son nuestras.

23 MoüETTE, op. cit. (nota 5), p. 145.

24 La Relation de captivité de Moüette es una obra singular, aunque hay otros relatos de cautiverio que se le suelen comparar, especialmente el del inglés Thomas Pellow, que se refiere parcialmente a la misma época y que también da cuenta de un cautiverio de larga duración. Los relatos de europeos cautivos en tiempos del sultán Mulay Ismail son varios, entre ellos los de Francis Brooks, Thomas Phelps y Simon Ockley. En otros casos, los textos europeos se refieren a la liberación de estos cautivos, como es el caso del libro de John Windus 
connu sous le nom de Roy de Tafilet, et de Mouley Ismaël ou Seméin ${ }^{25}$ son frere et son successeur à present regnant, y fue editada en París en $1683^{26}$. La información que contienen estas dos publicaciones le convierten en uno de los "historiadores" más relevantes para conocer los reinados de los primeros sultanes alauíes de Marruecos. Moüette reconoce a propósito de la segunda obra que su principal "informante" fue Bougiman, al que denomina "talbe et docteur de la loi" o "talbe" y "docteur de l 'Alcoran" 27 , y del que explica que, habiendo sido secretario del alcaide Cidan y participado en las conquistas de Mulay Rashid, y habiendo caído en desgracia tras el asesinato de Cidan, se había retirado de Fez el viejo (Fez el-Bali) a Fez el nuevo (Fez Jdid) donde subsistía como maestro pintor y escultor en yeso, un oficio que había ejercido en su juventud ${ }^{28}$. Moüette compartía oficio con Bougiman y llegó a trabajar con él durante tres años, de modo que tuvo la oportunidad de aprender de este marroquí lo que luego plasmó en su libro. No obstante, Bougiman también podría ser una figura retórica: no sería ni el primer ni el último sabio árabe que transmite conocimientos sobre su cultura al europeo que escribe o narra. Cide Hamete Benengeli y el cautivo Cervantes son ejemplos elocuentes para la escritura de ficción. En cualquier caso, Bougiman representa la figura del "informante": la obra histórica de Moüette podría haberse gestado a partir de los conocimientos adquiridos por el cautivo a través de su relación con múltiples norteafricanos, y no a través de lo transmitido por uno solo, pero de todas maneras, Bougiman representa la figura del "informante privilegiado", esa persona que le confiere autoridad al relato por su especial vinculación con la cuestión que se narra. En este caso, Bougiman es doblemente experto: en la religión musulmana, por tratarse de un experto religioso, y en el reinado de Mulay Rashid, por haber participado en sus acciones bélicas junto a uno de sus hombres de confianza.

La difusión de la Relation de Moüette ha sido notable desde su primera edición de 1683. En 1706 se edita en neerlandés en Leiden ${ }^{29}$, y en 1711 se edita en Londres en inglés. La obra de Moüette aparece en este caso en un libro editado por John Stevens, el titulado A new collection of voyages and travels into several parts of the world, una compilación de aventuras más o menos exóticas para deleite de un público ávido de

titulado A journey to Mequinez, o el de John Braithwaite, titulado The history of the revolutions in the Empire of Morocco. En el período anterior destacan los relatos que se refieren a cautiverios en Argel, como el libro del trinitario Pierre Dan (Histoire de Barbarie et de ses corsaires, publicada en París en 1649), y el relato de Emmanuel de Aranda (Relation de la captivité et liberté du sieur Emmanuel d'Aranda, publicado en Bruselas en 1656). La bibliografía sobre estos y otros relatos de cautiverio es numerosa. Véanse, por ejemplo: DuPRAT, A. y E. Picherot: Récits d'orient dans les littératures d'Europe: XVIe-XVIIe siècles, París, PUPS, 2008; y Moureau, F.: Captifs en Méditerranée (XVI-XVIIIe siècles): histoires, récits et légendes, París, PUPS, 2008.

25 Mouley Seméin es Mulay Ismail.

${ }_{26}$ Su título completo es Histoire des conquestes de Mouley Archy, connu sous le nom de Roy de Tafilet, et de Mouley Ismaël, ou Seméin, son frere, et son successeur à present regnant. Tout deux rois de Fez, du Maroc, de Tafilet, du Sus, etc. Chez Edmond Couterot, París, 1683. La edición que consultamos es la original de 1683, según el ejemplar digitalizado por Google Books, conservado en la Biblioteca Pública de Lyon.

27 Ibidem, preface. Se refiere a la actividad del taleb, el que ha memorizado el Corán, y con "docteur de la loi" y "docteur de l'Alcoran", quizá a la actividad de alfaquí.

28 Ibidem.

29 MoǘtтE, G.: De scheeps-togt van den Heere Moüette: uit Vrankryk na America ondernoomen, aan de kust van Barbaryen ongelukkig voleind... Leiden, 1706. 
publicaciones que refieran la suerte de los europeos en tierras lejanas y ajenas ${ }^{30}$. Las reediciones europeas de comienzos del siglo XVIII no extrañan, dado el interés que existía en Europa por este tipo de relatos que recogían la experiencia del cautiverio de los cristianos europeos en las tierras del Islam, y si tenemos en cuenta que muchos otros relatos, españoles, franceses, ingleses y holandeses, llegaron a ser publicados en varias lenguas y en distintas ciudades, algunos reeditados en diferentes siglos. Es el caso del que nos ocupa: editado en el siglo XVII, y reeditado en el siglo XVIII, en 1860 aparece un resumen en la revista Le Tour du Monde que contiene también resúmenes de las relaciones de Lemprière (siglo XVIII) y Richardson (siglo XIX) ${ }^{31}$. En 1927, ya en el siglo XX, la casa Mame de Tours vuelve a editar el relato de Moüette, esta vez con el prólogo de una tal Marquesa de Serres ${ }^{32}$. La mencionada aristócrata retrata Marruecos como el país "del rapto y la esclavitud", de modo que tampoco sorprende la publicación de un relato como el de Moüette en un contexto tan politizado como éste de 1927-28, que es el de la Guerra del Rif y el de la justificación de la ocupación franco-española de Marruecos. La última reedición del texto data de 2002, incluye prefacio y anotaciones de Xavier Girard, y ha sido realizada por la editorial Mercure de France ${ }^{33}$.

Daniel Nordman, escribiendo sobre la Relation de Moüette en su artículo biográfico sobre el autor, considera que el relato de cautiverio y de redención era un género de moda en la época, y que se encuentra "entre el clásico relato de aventuras, a veces amorosas, el relato moralizante, y la propaganda anti-berberisca de la Reforma católica" ${ }^{34}$. Nordman considera que este es un género que había sido "inventado en Argelia", y que "añade a la relación autobiográfica historias complementarias (aquí, seis novelas), aventuras galantes o edificantes" ${ }^{35}$. Las seis novelas del relato de Moüette a las que se refiere Nordman son: en el capítulo cuarto, el suplicio del español Francisco Carrión; en el capítulo séptimo, la historia de Bernard Bausset; en el capítulo duodécimo, la historia del portugués Dom Loüis Gonzalez; en el capítulo décimocuarto, la historia del español Dom Raphael Vetas; en el capítulo décimoquinto, las aventuras del Sieur de la Place; y en el capítulo décimosexto, la historia de dos renegados españoles ${ }^{36}$. Moüette habla sobre este tipo de historias y sobre su función en el texto, y dice que las incluye: "pour delasser l'esprit du lecteur des horreurs et des cruautez qu'il a leus dans les chapitres precedentes" 37 . Harrigan señala que, en ocasiones, estas "historias particulares" contienen tantos horrores y crueldades como

\footnotetext{
30 Stevens, J.: A view of the universe or a new collection of voyages and travels, vol. II, Londres, 1711.

31 Charton, É.: Le tour du monde. Nouveau journal des voyages, París, 1860.

32 Desconocemos la identidad de esta noble francesa. MoüETTE, G.: La captivité du Sieur Moüette dans les royaumes de Fez et de Maroc, Tours, A. Mame, 1927.

33 Moüette, G.: Relation de captivité dans les royaumes de Fez et de Maroc, ed. Xavier Girard, París, Mercure de France, 2002.

34 Nordman, op. cit. (nota 2), p. 711.

35 Ibidem.

36 Véase, para una caracterización de estas historias, la obra de TuRBET-DELOF, Guy: L'Afrique Barbaresque dans la littérature française du XVIIe siècle, Genève, Droz, 1973, pp. 263 y ss.

37 MoüEtTe, op. cit. (nota 33), p. 203.
} 
el propio texto principal ${ }^{38}$. En el caso de la historia de Bausset no se puede decir que éste contribuya a "relajar" en exceso "el espíritu del lector", pero sí es cierto que representa un hiato específico dentro de la obra, sobre todo porque se trata de la narración de un milagro, de un hecho extraordinario. Esto rompe un tanto con el tono narrativo general, que no traslada particular énfasis en sucesos sobrenaturales. La historia de Bernard Bausset es una "historia dentro de una historia", o, como se suele decir sobre estas breves noticias que contienen los relatos de cautiverio, empleando un concepto propio de la historiografía de la época, una "histoire particuliére". La Relation de captivité posee un hilo conductor general que es el cautiverio de Moüette, pero incluye, entre otras: 1) descripciones de varias ciudades marroquíes, entre ellas Salé y Mequinez; 2) notas históricas sobre los reinados de Mulay Rashid y Mulay Ismail; 3) historias de cautiverio de distintos personajes europeos; y 4) dos capítulos, el octavo y el noveno, sobre las condiciones de existencia de los esclavos europeos en Marruecos. La obra, como ya hemos señalado, también incluye un breve pero interesantísimo diccionario francés-árabe marroquí.

La historia de Bausset incuye otro personaje de interés. Es la española cautiva llamada María de la Concepción. Moüette dice que procedía de Sanlúcar de Barrameda, en Andalucía, y que había sido capturada junto a su marido durante un viaje desde La Mamora a España. Moüette explica que, "sin dañar su honestidad" (probable referencia a la práctica de relaciones sexuales con el sultán), esta andaluza había obtenido la benevolencia de Mulay Ismail, que le concedía "todas las gracias que ella le demandaba, tanto para los moros como para los cristianos" ${ }^{39}$. De esta manera, dice nuestro autor, se la llamaba la "madre común de todos los afligidos" marido se ocupaban de alimentar a las aves del sultán y tenían encargado el cuidado de los leones. Estas actividades son relevantes, ya que Moüette afirma que Bausset fue liberado gracias a la insistencia de María de la Concepción. En la escena de la liberación destacan dos aspectos: 1) el ascendiente de una mujer cautiva sobre el sultán (sin que medie ningún porqué de tipo sexual, como señala Moüette, aunque quizá sí afectivo), que seguramente pretende subrayar, de acuerdo con las lógicas de las sociedades androcéntricas de la época, la debilidad de la voluntad de Mulay Ismail, ya que retrata a un varón musulmán libre bajo la influencia de una mujer cristiana y cautiva; y 2) la traición de los pajes del sultán que compiten por ver quién será el primero que asista a Bausset, que dejan sólo a Mulay Ismail a la puerta del serrallo, y que reciben los golpes de cimitarra de un sultán profundamente ofendido (Moüette nos dirá que deja a ocho de ellos en el suelo, cubiertos de sangre y heridos), gesto que representa a un sultán traicionado por los suyos. No obstante lo dicho, Moüette aclara que en la liberación de Bausset también influyó el aprecio que Mulay Ismail sentía por él. De hecho, la Relación señala que en la hora de la partida de los cautivos liberados, el sultán le pidió varias veces que se quedara con él, y le dijo que él establecería su fortuna $^{41}$. Bausset le agradeció el gesto, pero finalmente abandonó Marruecos.

\footnotetext{
38 HARrigan, M.: Veiled encounters: Representing the Orient in 17th-century French travel literature, Amsterdam, Rodopi, 2008, pp. 230-231.

39 MoüETTE, op. cit. (nota 5), p. 98.

40 Ibidem.

41 Moüette, op. cit. (nota 5), p. 144.
} 


\section{LAS ESTRATEGIAS DISCURSIVAS DE GERMAIN MOÜETTE}

La veracidad de los relatos de cautiverio y de redención es una cuestión que suele preocupar a los investigadores. Es indudable que la mayor parte de los conocidos hasta la fecha mezclan realidad y ficción (u observación y convención, como dice Daniel Nordman ${ }^{42}$ ), pero es complicado establecer qué episodios son memorias de experiencias reales y cuáles reflejan convenciones literarias y discursivas, estandarizaciones y estereotipos ${ }^{43}$. En relación con el tema de la conversión, Claire Norton considera que las narraciones sobre la conversión forzada son tropos figurativos y retóricos que cumplen funciones particulares, y subraya que habría que fijarse en los textos y contextos en los que se introducen ${ }^{44}$.

Las estrategias discursivas que le otorgan credibilidad a este relato de Moüette son múltiples. En el prefacio de la obra, y haciendo especial mención a la historia de Bernard Bausset, Moüette se presenta como transmisor de una historia veraz:

Je rapporte aussi dans l'histoire d'un autre esclave françois, un évenement qui tient tellement du miracle, que j'ay jugé à propos d'y joindre l'attestation en forme de la verité de la chose, signée de plusieurs témoins oculaires dignes de foy du nombre desquels j'étois. En effect, depuis le miracle de Daniel, il n'y a point d'exemple si visible de l'assistance divine, que celuy de ce pauvre captif ${ }^{45}$.

La manera en que Moüette reafirma la veracidad del relato es interesante. La certificación que aporta para subrayar que la historia es verídica viene avalada por la firma de veinte personas. En esta lista se encuentra el propio Moüette, pero también algunos religiosos y comerciantes, todos ellos franceses. Moüette indica la procedencia geográfica concreta de todos ellos, a excepción de sí mismo, y las actividades de tan sólo cuatro de los firmantes. De este modo sabemos que dos, Bernard Monel e Ignace Bernede, son religiosos de la Orden de la Merced, y que dos otros son mercaderes, los llamados Toussaint Boyer y Nicolas Boyer, quizá hermanos, o padre e hijo. Los catorce nombres que aparecen tras del suyo son los de compañeros de cautiverio en Mequinez, liberados también por los padres de la Merced. La nota viene firmada en Tetuán el 8 de abril de $1681^{46}$. Tetuán -llamada Toutöuan en este libro- es una ciudad con un papel importante en el tráfico de esclavos ${ }^{47}$, y una de las escalas del viaje de regreso de Moüette. Moüette sitúa la acción el día 15 de febrero, diez días antes de su partida de Mequinez. Los hombres que firman para Moüette son calificados por él, en un lenguaje puramente jurídico, como "testigos oculares" y "dignos de fe". En un momento del relato, Moüette asegura haber visto todo el episodio, junto con otros

42 Nordman, op. cit. (nota 2), p. 711.

43 La obra de Guy Turbet-Delof citada con anterioridad es ejemplar en este sentido.

44 Norton, C.: "Lust, greed, torture, and identity: Narrations of conversion and the creation of the Early Modern renegade". Comparative studies of South Asia, Africa and the Middle East, 29,2 (2009), pp. 259-268, p. 260.

45 Moüette, op. cit. (nota 5), preface.

46 MoüetTe, op. cit. (nota 5), p. 100.

47 Ver El JetTI, M.: “Tétouan, place de rachat des captifs aux XVIe et XVIIe siècles", Cahiers de la Méditerranee, 87 (2013), pp. 147-158. 
cautivos, a través de unos agujeros que tenía el muro que mediaba entre la prisión y el foso de los leones ${ }^{48}$. Es particularmente relevante que hable de "attestation" ¿Es posible que en algún momento Moüette y los padres de la Merced ambicionaran que a Bausset se le reconociera oficialmente como protagonista de un milagro? Lo más probable es que Bausset sea un personaje de ficción o que siendo él real, su peripecia sea parcial o totalmente ficticia, con lo que la alusión a la certificación del milagro sería una más de las estrategias discursivas del autor del texto, quizá la más relevante: podríamos decir que no le basta con instrumentalizar un ejemplo bíblico, como ya habían hecho y harán otros escritores, sino que también incluye aspectos formales reclamados por la Iglesia Católica con ocasión del reconocimiento de actos milagrosos, como el testimonio de los testigos presenciales debidamente avalado por sus firmas.

Los aspectos formales evaluados son característicos de géneros cultos que seguramente conocían con cierto detalle los religiosos de la Merced: nos referimos a las acta martyrium o actas de los mártires, y a los martirologios. En estos textos de carácter biográfico es bastante usual el tono jurídico, y son frecuentes las referencias a los testigos y a las exhortaciones de los correligionarios del mártir. Enrique Fernández ha señalado que "es característico de la literatura testimonial aumentar su veracidad adoptando formas y contenidos de géneros de reconocido prestigio en la época", y que "esta inclusión de hechos milagrosos realza el carácter de testimonio verídico de la obra"49. La literatura cristiana contiene un buen caudal de información sobre la vida y la muerte de mártires de la fe en el norte de África, tanto en la época romana como en la Edad Media y Moderna, y la literatura europea del siglo XVII presenta la vida y la muerte de algunos europeos cautivos en el norte de África como la vida y la muerte de los mártires de otros tiempos, no sólo porque considere que los cautivos ejecutados son mártires, sino también porque el uso de estos géneros literarios, de las biografías de santos y mártires, es un punto fuerte de las estrategias discursivas de los autores, estrategias vinculadas con los fines políticos que persigue la construcción del mártir y del héroe.

Moüette afirma haber visto a Bausset en el foso, y también saber de su destino, a través del Padre Monel, uno de los frailes redentores. Este le dice que ha pedido el hábito en un convento de su orden y que retornará a Marruecos con Monsieur de Saint Amand, el embajador del rey francés frente al sultán. La intención de Bausset es volver con el embajador para servirle de mediador o traductor (truchement, trujimán). Estos datos que ofrece Moüette sobre la embajada del barón de Saint Amand enviada por Luis XIV se refieren a un hecho histórico, ya que el mencionado viaje tiene lugar en 1682, un año después de la liberación de los cautivos. En concreto, la misión de Saint Amand, en la que por cierto fracasa, será la ratificación por parte de Mulay Ismail de un acuerdo con Luis XIV que no se llegará a firmar porque perjudica gravemente los intereses de Argel.

\footnotetext{
48 MoüEtTe, op. cit. (nota 5), p. 97.

49 FERnÁNDEZ, E.: "Los tratos de Argel: obra testimonial, denuncia política y literatura terapéutica", Cervantes: Bulletin of the Cervantes Society of America, 20, 1 (2000), p. 13.
} 


\section{BERNARD BAUSSET O LE NOUVEAU DANIEL: LA CONSTRUCCIÓN DE UN MÁRTIR CRISTIANO EN EL SIGLO XVII}

Germain Moüette asegura que "tras el milagro de Daniel, no hay ningún ejemplo tan visible de la asistencia divina como el de este cautivo Bernard Bausset" ${ }^{50}$. Esta referencia del autor remite al Libro de Daniel de la Biblia, y nos pone en la pista del pasaje al que se refiere su texto sobre Bausset, el que narra el cautiverio de Daniel en Babilonia y su castigo en el foso de los leones (Dn. 6: 11-25, y Dn. 14: 28-42). Esta historia del Antiguo Testamento nos remite a una tradición judeo-cristiana ${ }^{51}, y$, significativamente, no se trata de un relato de resistencia en la fe cristiana, sino en la fe judía. Las historias de Daniel y Bausset presentan ciertas similitudes. Los dos eran cautivos -Daniel había sido conducido a Babilonia y Bausset a Marruecos; los dos accedieron a puestos de trabajo relacionados con la docencia y vivieron en el palacio real, donde estuvieron cercanos al monarca- Daniel, en la corte de Nabucodonosor II, Bausset en el palacio del sultán Mulay Ismail; y los dos fueron arrojados al foso de los leones. Los leones de Bausset doblan en número a los de Daniel: el cautivo judío se enfrentó a siete leones, y el cautivo francés a catorce. En ambos casos, los leones estaban hambrientos. En las dos historias, la supervivencia del cautivo hace que el monarca reconozca la superioridad de la religión del prisionero sobre la propia. En el caso de la historia de Daniel, el rey babilonio afirma que no hay otro Dios fuera del Dios de Daniel y que él es el verdadero. Las dos historias finalizan con correligionarios del monarca arrojados al foso y devorados por los leones. En el caso de la historia bíblica, los arrojados al foso son los causantes de la condena. En el caso de Bausset, Moüette señala que

algunos días después, los leones no tuvieron el mismo respeto por tres fequers, o sabios de la ley de Mahoma, que se habían atrevido a hacerle al rey algunos reproches sobre sus crueldades, él les hizo lanzar al mismo parque, donde fueron enseguida despedazados ${ }^{52}$.

La intención del episodio es bastante clara: se trata de mostrar que los leones del sultán respetaron la vida del hombre cristiano, pero no respetaron la vida de los fieles y sabios musulmanes. La religión cristiana sale vencedora frente a la religión musulmana: el Dios de los cristianos es capaz de salvar a sus fieles, y el Dios de los musulmanes carece de poder para salvar a los suyos, ni siquiera siendo éstos hombres de los que se espera una especial valía ${ }^{53}$.

La presencia de Bausset en el foso de los leones no es la única que recuerda el episodio bíblico. En el relato sobre el franciscano italiano Andrés de Espoleto, martirizado en Fez en 1532 por predicar el cristianismo entre los musulmanes, Espoleto es

\footnotetext{
50 Mouette, op. cit. (nota 5), preface.

51 Es importante tener en cuenta que la historia de Daniel y Nabucodonosor también aparece, en algunos hadices, en la tradición musulmana, y en la literatura rabínica judía.

52 Moüette, op. cit. (nota 5), p. 99.

53 Con fequers puede Moüette referirse a los "alfaquíes", expertos en la ley islámica y en el Corán, o a los "faquires", miembros de las hermandades sufíes. Su aclaración ("sabios de la ley de Mahoma") encaja bien con el primer término, y la transcripción fonética con el segundo.
} 
encerrado en un pozo con un león que no le ataca ${ }^{54}$. Enrique Fernández ha señalado que este episodio del martirologio de Espoleto recuerda una escena de Los tratos de Argel, de Cervantes, en que un león manso guía a un cautivo que pretende huir de sus dueños. En el relato de cautiverio de Thomas Le Gendre de 1614-15 ocurre lo mismo: dos cautivos son guiados por un león en su fuga ${ }^{55}$. Fernández encuentra que en Los tratos de Argel existen numerosas adaptaciones del discurso religioso para representar memorias del cautiverio, como el citado de Cervantes ${ }^{56}$. Esto es fácil de explicar a partir de la formación intelectual de Miguel de Cervantes, pero... ¿Y en el caso del cautivo francés Germain Moüette?

La Iglesia Católica reconoce varios mártires llamados Daniel, pero existe un ejemplo, precisamente norteafricano, en el que aparece uno de los elementos más relevantes presentes en el relato de Bausset, el de la conversión forzada, que es un leit motiv de los martirologios cristianos, y que es uno de los motivos centrales en los relatos de cautiverio en Berbería de los siglos XVI al XIX. San Daniel es uno de los siete mártires cristianos que encontraron la muerte en la ciudad de Ceuta en 1227. Daniel era un fraile menor, ministro de Calabria, que había viajado con otros seis frailes de su congregación al norte de África para predicar. Hoy en día se le venera como patrón de la ciudad. Las hagiografías indican que fue martirizado mientras se le forzaba a convertirse al Islam y apostatar de su fe. La figura de los "siete mártires" recuerda indudablemente la de los "siete durmientes de Éfeso", una tradición presente en la literatura cristiana, y en el Corán como las "gentes de la caverna" o "los compañeros de la caverna" (Ahl al-Kahf o Ashâb al-Kahf, azora 18, aleyas 9-26), que explica tanto lugares de culto del Islam - especialmente, en el norte de África - como del Cristianismo. La certificación del martirio de estos siete frailes menores en el siglo XIII bien pudo contribuir a sellar la cristianización de un lugar de culto musulmán o reafirmar un lugar de culto cristiano pre-islámico ${ }^{57}$, y a sancionar la cristiandad del lugar tras la ocupación ibérica de este puerto norteafricano. La fecha de canonización de San Daniel es aún más significativa, ya que tiene lugar por parte de León X en 1516, una fecha de interés en relación con el expansionismo ibérico hacia el norte de África. Indudablemente, la creación de mártires cristianos está vinculada con la afirmación del Cristianismo frente al Islam, pero no está exenta de fines políticos. San Daniel de Ceuta es lo que se ha llamado un "mártir de frontera": el proceso de santificación de

54 Véase, Olave, A. de: Passio gloriosi martyris beati patris fratris Andree de Spoleto ordinis Minorum regularis obseruantie pro Catholice fidei veritate passi in Affrica ciuitate Fez, 1532. Olave, A. de (F. Anthoine de Olave): Hystoire et lettres du glorieux et bienheureux frère André de Spolete de l'ordre des freres Mineurs de la régulière observance... lequel a souffert martyre en la cité de Fez... Imprime fut cestuy petit propos A la resqueste du marchant Jehan Barril...., Toulouse, Jacques Colomies Imprimeur, 1532. CASTRIES, H. de: Les Relations du martyre d'André de Spolète, Fez, 1532. París, E. Leroux, 1918. Desmazières, M.: Un Martyr franciscain à Fès au XVIe siècle. André de Spolète, né André della Rosa, París, Editions franciscaines, 1938. Desmazières, M.: Sur la terre du Maghreb. La vie et la mort de frère André de Spolète, martyr franciscain à Fès au XVIe siècle, París, Editions franciscaines, 1942.

55 Feucher, C.: Mazagan, 1514-1956, París, L'Harmattan, 2011, p. 63.

56 FERnÁndeZ, op. cit. (nota 49), p. 13.

57 Podría ser anterior a la expansión del Cristianismo si es significativo que Plinio hable de Septem fratres en Ceuta. 
su experiencia en el norte de África está estrechamente relacionado con la afirmación de la cristiandad de la ciudad de Ceuta, posiblemente para legitimar su ocupación.

Lo visto hasta aquí nos sugiere dos preguntas: ¿Cómo se construye un mártir en el siglo XVII? ¿A qué fines responde la construcción de un mártir, bien que sólo sea la de un mártir literario? La construcción discursiva del mártir se efectúa en el caso de Bausset a partir de la identificación del cautivo y de su castigo con un personaje y una narración bíblica concreta: el episodio de Daniel en el foso de los leones. Bausset es una versión de Daniel, de ahí que el propio Moüette le denomine "un nouveau Daniel" 58 . Los mártires de frontera de otros tiempos también sirven de ejemplo para los cautivos, en particular como materia prima para la construcción de nuevos mártires a partir de las experiencias de los cautivos, para la conversión del cautivo en mártir, aunque sólo sea sobre el papel. En este sentido debemos recordar que en uno de los relatos españoles sobre el norte de África más importantes del siglo XVI, la Topographia de Argel de Diego de Haedo (cuyo autor es Antonio de Sosa) ${ }^{59}$, encontramos ya una serie de vidas de mártires en conexión con la cuestión del cautiverio, y que una de las obras más relevantes del siglo XVI sobre el norte de África, el Diálogo de los mártires de Argel de Antonio de Sosa ${ }^{60}$, contiene copiosas referencias a la cuestión del martirio en Berbería. La formación de estos dos autores, religiosa, de la orden benedictina el primero, y posiblemente vinculado a la Orden de San Juan de Jerusalén (Orden de Malta) el segundo ${ }^{61}$, hace que no extrañe su manejo de tales recursos ideológicos y narrativos, pero... ¿Y en el caso del cautivo Moüette?

En las vidas de mártires, uno de los principales aspectos del martirio es la tortura física. La relación de Moüette no nos informa con excesivo detalle sobre toda esa "suerte de medios" que, según dice el autor, el sultán utilizó para obligar a Bausset a renegar de su fe $\mathrm{fe}^{62}$, pero sí ofrece algunos datos sobre los castigos que recibió el preso cuando mostró su resistencia. Moüette escribe que el sultán:

58 MoÜETTE, op. cit. (nota 5), p. 97.

59 Haedo, D. de: Topographia e historia general de Argel, Valladolid, 1612. Los trabajos de Camamis, Sola y Garcés corrigen la autoría de esta obra, que se le atribuye a Antonio de Sosa. Véanse: GARCÉs, M. A.: Cervantes in Algiers: A Captive's Tale, Nashville, Vanderbilt, 2002; Garcés, M. A.: Cervantes en Argel. Historia de un cautivo, Madrid, 2005 y GARcÉs, M. A.: An Early Modern Dialogue with Islam: Antonio de Sosa's Topography of Algiers (1612), Notre Dame, UNDP, 2011; CAMAMIS, G.: Estudios sobre el cautiverio en el Siglo de Oro, Madrid, Gredos, 1977; y Sola, E.: "Miguel de Cervantes, Antonio de Sosa y África", Actas del I Encuentro de Historiadores del Valle del Henares, Alcalá de Henares, 1988, pp. 617-623, y SolA, E.: “Antonio de Sosa: Un clásico inédito amigo de Cervantes (historia y literatura), Actas del primer coloquio internacional de la Asociación de Cervantistas, Barcelona, 1990, pp. 409-412.

60 Sosa, A. de: Diálogo de los mártires de Argel, edición de Emilio Sola y José María Parreño, Madrid, Ediciones Hiperión, 1990.

61 Aunque son varios los historiadores que hablan de Antonio de Sosa como benedictino, las investigaciones de María Antonia Garcés le atribuyen una membresía diferente, en la Orden de Malta: GARCÉs, op.cit. (nota 59).

62 Los renegados son los cristianos que apostatan y se convierten al Islam en tierras de Berbería. Bennassar ha escrito lo siguiente sobre su procedencia: "centaines de milliers de chrétiens... on franchi ces frontières vers l'est ou le sud, happés par le mascaret islamique; le plus souvent pris contre leur gré sur terre ou sur mer; souvent aussi livrés régulièrement, encore enfants, aux agents de la Sublime Porte...; mais aussi, plus que on ne croit, transfuges volontaires, soldats et marins déserteurs des armées et des flottes chrétiennes et d'abord de celles du Roi Catholique; marins-pêcheurs ou paysans pauvres des péninsules méditerranéennes et marins du nord qui voyaient dans les cités barbaresques les lieux du pouvoir et richesse; prêtres ou religieux défroqués saisis par les vertiges erotiques des palais et des jardins secrets entrevus lors d'une captivité antérieure", 
(...) hizo que le desnudaran, y que dos negros, cada uno con una empuñadura de correas, le dieran más de quinientos golpes, de suerte que hicieron que su cuerpo se pusiera más negro que el carbón ${ }^{63}$,

y que "después de haberle puesto en este estado, le envió con dos grandes cadenas a nuestra prisión para hacerle pensar allí" 64 .

En esta parte de la obra encontramos ciertos aspectos de interés. Por un lado, los que infligen el primer castigo a Bausset, la flagelación, son dos hombres negros de la guardia de Mulay Ismail, del llamado abid al-bukhari. La demonización de la figura del sultán marroquí suele completarse, en este y otros relatos, con referencias a la ferocidad de sus huestes, sobre todo de su guardia negra. Por otro lado, la flagelación nos remite a la vida de Cristo, así como también un golpe de lanza que recibe Bausset. Esta es, podemos decir, la segunda referencia bíblica de peso, cierta identificación con Cristo con un claro propósito efectista. Otra de las cuestiones relevantes es la manifestación de la indiferencia frente a la muerte y la suerte del cuerpo. E incluso, la ejecución de ciertas acciones personales cercanas al "suicidio heroico". En su relato, Moüette deja bien claro que Bausset no recibe de forma pasiva el martirio: no es arrojado al foso de los leones, sino que se precipita él mismo. La actitud pasiva ante la muerte es una característica del martirio cristiano, pero la recepción pasiva del castigo no está en el ánimo de Bausset. De hecho, muestra indiferencia hacia la muerte y le dice al sultán que no le podrían dar una muerte que le hiciera más glorioso, y que preferiría que su cuerpo sirviera de pasto a los leones, que ver su alma presa de los demonios. Bausset, escribe Moüette,"se lanza él mismo en medio de catorce leones, de un tamaño prodigioso, y que no han comido en tres días" ${ }^{65}$. Como vemos, el autor se preocupa por señalar la valentía del mártir y construye al héroe. La distinción entre la preocupación por la ventura del cuerpo y la del alma es típicamente cristiana: Bausset manifiesta que el alma está por encima del cuerpo, y que la muerte corporal no le importa. Moüette insiste en esta concepción dual de la persona propia del cristianismo cuando refiere quiénes se ocuparían de las heridas del cuerpo y del alma de Bausset; por un lado menciona a "Nuestra Señora, protectora de los cautivos" y a Santa Ana, y por otro a un tal Prieur, cirujano de Poitiers ${ }^{66}$, muy probablemente también cautivo. "Nuestra Señora" se refiere a la Virgen María, en concreto en su advocación de la Merced, y la devoción por Santa Ana, la abuela de Jesús, que es bastante común en el catolicismo en cualquier época, tendrá su relevancia posterior en la obra, cuando Bausset deposite una ofrenda como acción de gracias en su santuario de Le Castellet, en su Provenza natal.

\footnotetext{
Bennassar, B.: "Conversion ou réniement? Modalités d'une adhésion ambiguë des chrétiens à l'Islam (XVIeXVIIe siècles)", Annales. Économies, sociétés, civilisations, 6 (1988), p. 1350. Véanse también, BENNASSAR, B. y L. Bennassar: Les Chrétiens d'Allah. L'histoire extraordinaire des renégats (XVIe-XVIIe siècles), París, Perrin, 1989; González-Raymond, A.: La croix et le croissant. Les inquisiteurs face à l'islam, 1550-1700, Paris, CNRS, 1992, y Scaraffia, L.: Rinnegati. Per una storia dell'identità occidentale, Roma, Laterza, 1993.

63 MoüETTE, op. cit. (nota 5), p. 94.

64 Ibidem, p. 94-95.

65 Ibidem, p. 96.

66 Moüette, op. cit. (nota 5), p. 99.
} 


\section{DANIEL EN EL FOSO DE LOS LEONES Y LOS LEONES DEL SULTÁN MULAY ISMAIL: IMÁGENES EUROPEAS DE LA MONARQUÍA MARROQUÍ}

Mulay Ismail es un sultán marroquí cuya figura se ha conformado a través del mito, la leyenda y la historia ${ }^{67}$. Los textos europeos contribuyeron a formar una imagen del sultán que acentúa $-\mathrm{y}$, a veces, exagera- su poder, pero sobre todo su crueldad: se le llama con frecuencia "sanguinario", "sediento de sangre", "tirano"... La posición del cautivo cristiano en las sociedades del norte de África era débil, y para subrayar este hecho, el relato de Moüette construye una determinada imagen del sultán Mulay Ismail. En buena medida Moüette nos presenta un sultán poderoso principalmente con el objeto de acentuar la victoria de Bausset: exalta al rival para magnificar la gesta. Lo mismo se puede decir de los leones, que no sólo son las fieras que en efecto son, sino que también están hambrientos desde hace días.

La posesión de leones por parte del sultán es un hábito propio de la dinastía Alauí que inaugura Mulay Ismail y que se ha mantenido hasta el siglo XX: de hecho, el anterior sultán de Marruecos, el alauí Hassan II, envió los últimos leones reales al zoológico de Temara, en las inmediaciones de Rabat, leones que previamente eran custodiados en el palacio real. En los relatos de cautiverio y de redención europeos de los siglos XVI al XVIII, los leones aparecen como instrumento de castigo de los sultanes, particularmente de Mulay Ismail y los alauíes, pero también como obsequio por parte del sultán a los reyes europeos. El papel del león como instrumento de castigo del sultán persiste a lo largo del tiempo, y también forma parte de las representaciones europeas de los monarcas marroquíes, sobre todo de su implacabilidad. Así, por ejemplo, en 1841, el francés Conrad Malte-Brun escribe sobre los judíos de Marruecos:

on les condamne souvent à être jetés, comme Daniel, dans la fosse aux lions, à Maroc; mais comme les gardiens des lions sont juifs eux-mêmes, il en arrive rarement des malheurs; les gardiens ont soin de bien nourrir les lions, et de ne laisser leurs compatriotes qu'une nuit dans la fosse ${ }^{68}$.

En la primera década del siglo XX, fuentes españolas y francesas indican que el disidente Bu Hamara, llamado "El Roghi", fue arrojado a los leones del sultán ${ }^{69}$. En cuanto al envío de leones marroquíes a Europa, en 1680, el propio Mulay Ismail envía una embajada y ciertos presentes a Luis XIV, entre ellos, un león, una leona, una tigresa y cuatro avestruces que le lleva el Hajj Mohamed Temim, vice-gobernador de la ciudad de Tetuán ${ }^{70}$.

67 La bibliografía que informa sobre Mulay Ismail es copiosa, pero aquí daremos cuenta únicamente de algunos de los estudios específicos: Nekrouf, Y.: Une amitié orageuse: Moulay Ismaïl et Louis XIV. París, Albin Michel, 1987. Veronne, C. de la: Vie de Moulay Ismail, roi de Fès et de Maroc. París, P. Geuthner, 1975. Plantet, E.: Moulay Ismael: Empereur du Maroc, et la princesse de Conti. París, E. Jamin, 1912.

68 Malte-Brun, C.: Géographie universelle, París, Furne, 1841, p. 595.

69 García Figueras, T.: Marruecos. La acción de España en el norte de África, Madrid, Fe, 1941, p. 116.

70 NéKrouf, op. cit. (nota 67), p. 93. 
Los leones ocupan un lugar importante en el imaginario de los marroquíes, y también en el de los europeos que escriben sobre Marruecos en distintas épocas. Rosenberger no se equivoca cuando señala que en aquel país, los leones son fuente de "peligros, miedos y mitos" ". En las dos orillas del Mediterráneo, tanto en la Europa cristiana como en el norte de África musulmán, la figura del león se ha utilizado para representar el poder de un personaje varón de cierta significación política y religiosa, bien sea un sultán, un rey, un jerife, un aristócrata, un santo... Es interesante notar aquí que en Marruecos, antes de estar ligados a los sultanes, los leones son animales vinculados con los santos y los jerifes, sobre todo en los relatos hagiográficos. En la contemporaneidad, Abdelkrim el-Khattabi, de condición jerifiana, recibió el apelativo de "león del Rif". Mulay Abdsalam Ibn Mashish, santo y jerife idrisí muy venerado en todo el norte de Marruecos, descendiente del Profeta Mahoma a través del santo Mulay Idriss, lleva el apelativo amazigh/bereber de Mizwar (león), y así se denomina también a los líderes de los "hijos del santo" (ulad siyyid), en el caso de otras líneas jerifianas del país, distintas de la alamí, y también de la alauí gobernante hoy en día. Ángel Cabrera, un naturalista español, escribe en la época del Protectorado que en Chefchauen, en el norte de Marruecos, le contaron una leyenda que dice que todos los años, con motivo de la peregrinación al santuario de Mulay Abdsalam "un león baja de las montañas de Gomara, y pasando por la tribu de El Ajmás, llega hasta el venerado sepulcro para rezar, hace el viaje de noche, de modo que lo ven pocas personas, y éstas le dejan el paso libre, sin molestarlo, en consideración a que se trata de una fiera creyente". Cabrera también señala que en otro tiempo, no era raro ver en Marruecos o en Argelia, "algún león viejo, a veces ciego, en poder de una cofradía o de un morabito"72. Las hagiografías señalan que los grandes místicos sufies, como Abu Madyan o Abu Yazza, domaron leones. En la historia del Cristianismo también encontramos ejemplos de santos domadores de leones, como San Jerónimo. Igualmente, conviene recordar el ejemplo del mártir cristiano San Ignacio de Antioquía, que pereció devorado por un león, y el ejemplo de todos los mártires cristianos que de acuerdo con la literatura hagiográfica cristiana-sobre todo, actas de mártires - fueron arrojados a los leones. Este es el principal modelo de la historia de Bausset. En las hagiografías de los sufíes norteafricanos encontramos múltiples versiones de la figura del león, ya sea la del león manso, la del león domado, el león feroz... La figura del león manso, que es la propia de la historia de Bausset, aparece en numerosas vidas de santos, tanto cristianas como musulmanas. La mansedumbre de los leones representa el reconocimiento de la superioridad del santo, y cierta reestructuración del orden natural tras de la cual se encuentra la voluntad divina. En este caso, el dominio de Baus-

71 Rosenberger, B.: "Lions, saints et sultans au Maroc", en Milieux naturels, espaces sociaux: Études offertes à Robert Delort. París, Publications de la Sorbonne, 1997, p. 219. En 1958, André Vovard publica una obra titulada Les lions de l'Afrique du Nord au temps des pirates barbaresques que, lamentablemente, no hemos podido consultar. La referencia es: Vovard, A.: Les lions de l'Afrique du Nord au temps des pirates barbaresques, Bordeaux-París, Ed. Bières, 1958. En uno de sus artículos, Guy Turbet-Delof analiza la existencia de leones en Marruecos a partir de las noticias de algunos relatos de cautivos y embajadores. Ver TuRBETDELOF, G.: "Deux exemples de modification interprétative: Les representations de Satan dans la literature et les arts graphiques français relatifs au Maghreb du XVIe au XVIIe siècle”, en DuBoIs, C.-G.: L'imaginaire du changement en France au XVI siècle, vol. 2, Bordeaux, Presses Universitaires de Bordeaux, 1985 , p. 67.

72 Cabrera, Á.: "Su majestad el león se bate en retirada", Caras y caretas, 2 de febrero (1935), p. 5. 
set no representa únicamente el triunfo del cautivo sobre el león, sino el triunfo de la religión del cautivo sobre la religión del sultán, y por tanto sanciona la institución de un nuevo orden: el débil vencedor sobre el fuerte, el esclavo sobre el amo, el súbdito francés frente al sultán marroquí... La posesión de leones por parte del sultán Mulay Ismail, y las notas sobre su uso como instrumento de castigo, también colaboraron en la formación de la imagen dura que los europeos dieron de él. Precisamente, la Relation de captivité de Germain Moüette es una de las principales fuentes europeas que informan sobre estos leones ${ }^{73}$.

\section{LA RESISTENCIA A LA APOSTASÍA DEL CRISTIANISMO Y A LA CONVERSIÓN AL ISLAM}

Indudablemente, el principal tema que trata el relato de Bausset es el de la resistencia en la fe. Bausset se opone a los requerimientos del sultán con firmeza: se niega a apostatar de su fe cristiana y rechaza convertirse al Islam. La historia de Bernard Bausset propone un modelo relevante para los cristianos, especialmente para los cautivos en Berbería, que le pueden tomar como ejemplo (la libertad es la recompensa para este cuasi-mártir de la fe, no-apóstata y no-renegado, fiel y perseverante católico), y para los potenciales donantes de limosnas destinadas a la redención, que pueden sentir compasión por él y pensar que los católicos cautivos merecen, como premio a su virtud, un esfuerzo económico. Este es sin duda el principal objetivo de buena parte de la literatura de factura religiosa sobre el norte de África: justificar y ensalzar las actividades de los Mercedarios y de los Trinitarios, estigmatizar el Islam y la cultura de las sociedades del norte de África, y procurar que los donantes sean generosos con lo donado. Los relatos de cautiverio y redención forman parte de la propaganda religiosa de las órdenes redentoras, pero también de la propaganda política de los Estados que las albergan. En este último sentido se opta por la depreciación o la exaltación del enemigo, según convenga, y se subraya la hostilidad del Otro hacia el cristiano. En este relato que ofrece un doble punto de vista religioso y político sobre el cautivo tiene lugar una doble construcción como mártir y como héroe. No obstante, la figura de Bausset presenta cierta especificidad, porque, lejos de comunicar que a quienes se resisten en la fe les espera la muerte, en este relato, Bausset representa el triunfo de la fe y obtiene la vida como recompensa. Moüette no insiste en exceso en la identidad "nacional", pero sí en la identidad religiosa como diferencia fundamental en la victoria del cautivo frente al sultán.

Las historias de conversión al Islam que contienen los relatos de cautiverio y redención suelen ser de carácter autobiográfico o biográfico, al estar escritas en primera o en tercera persona, y suelen dar cuenta de 1) los intentos de conversión a través de la tortura, o 2) la resistencia frente a la conversión a través de actos sacrificiales o heroicos. Es bastante raro encontrar narraciones que informen sobre la apostasía o las conversiones voluntarias, lógicamente porque los tribunales europeos actuaban contra los renegados que regresaban a los reinos cristianos, y porque la conversión

73 Moüette, op. cit. (nota 5), p. 95. 
religiosa se entiende como una victoria política del oponente. La historia de Bausset exalta el heroísmo individual, pero no dibuja un perfil netamente individual, sino el perfil de un individuo que representa una colectividad: la comunidad de creyentes cristianos. Lo que se plantea en el relato es una puesta en escena de la manera en que se entiende el conflicto latente en el Mediterráneo: Cristianismo vs. Islam, Cristiandad (representada por los monarcas cristianos) vs. Berbería, una pugna territorial y religiosa. Esta escenificación tiene lugar a través del duelo de individualidades: el conflicto entre el cautivo y el sultán es un tema de singular efectismo. Moüette narra la victoria del cautivo, la victoria de la religión católica y la victoria de la Cristiandad. Esta es una historia no exenta de un providencialismo católico: "Dios se sirvió de la crueldad de Mouley Seméin", escribe Moüette, "para hacer manifiesto el particular cuidado de él hacía de sus servidores, y para fortificar nuestra fe a través de un insigne milagro"74. Los musulmanes no son sujetos de su propia Historia, sino instrumentos del Dios de los católicos, que los utiliza para fines piadosos y políticos.

¿Qué es lo que sabemos sobre las circunstancias en que los cristianos renegaban de su fe y se convertían al Islam? Las fuentes que nos permiten perfilar una respuesta son bastante distintas: disponemos de los relatos de cautiverio y redención, de crónicas e impresos, pero también de los testimonios que dieron los cautivos, especialmente los renegados o los sospechosos de haber apostatado, frente al Santo Oficio. La mayor parte de los renegados o los sospechosos de apostasía que dieron testimonio frente a los inquisidores en España subrayaron que su conversión había sido forzada, y que había sido ineludible. La mayoría -como explica Bennassar- dice haber renegado tras haber sido maltratado, o haber apostatado con el objeto de poder preparar una fuga $^{75}$. Bennassar considera incontestable que la mayor parte de las apostasías fueron obtenidas por la fuerza y a través del ejercicio de la violencia, sobre todo cuando se trataba de niños y de adolescentes ${ }^{76}$. Los dueños de los esclavos podrían haber estado interesados en su conversión al Islam por diversas razones: entre ellas, la de inscribir una marca indeleble en su cuerpo, la circuncisión (también el cambio de vestimentas marcaba), que hiciera más complejo su regreso a la cristiandad y que disminuyera el riesgo de evasión ${ }^{77}$. Era frecuente que incluso los que habían renegado voluntariamente se presentaran en los tribunales del Santo Oficio y obtuvieran una absolución ad cautelam. Estas ideas las comparte una mayoría de los investigadores que trabajan sobre este tema. Claire Norton advierte, no obstante, que los relatos de conversiones forzadas presentan ciertas contradicciones con lo que es normativo en el Islam sobre esta cuestión. Resumiendo los argumentos de Norton, podemos subrayar que: 1) la ley islámica prohíbe la conversión por la fuerza y considera inválidas las obtenidas de tal modo; 2) en teoría, los esclavos maltratados deben obtener la libertad; 3) el Corán establece que los esclavos conversos deben ser liberados de inmediato, existía cierta presión social al respecto, y esto iba claramente contra los intereses económicos del dueño, cosa que desaconsejaría la conversión; 4) los esclavos maltratados y torturados perdían valor, tanto como mano de obra, como en lo que se refiere al precio de

\footnotetext{
74 Moüette, op. cit. (nota 5), p. 93.

75 Bennassar, op. cit. (nota 62, 1988), p. 1351.

76 Ibidem, p. 1358.

77 Ibidem, p. 1360.
} 
su posible redención; y 5) en el Magreb de la época existían muchas muestras de la tolerancia religiosa ${ }^{78}$. Miguel Ángel de Bunes indica que "el tema de los renegados es una demostración más de que para una parte importante de la población los principios pueden ser trocados por la comodidad, el miedo, la conveniencia o la necesidad"79, y que tanto los inquisidores como los musulmanes consideraban que "arrebatar un miembro al otro credo religioso era una cuestión de prestigio y de autenticidad de su religión" ${ }^{80}$. Las ideas reseñadas nos permiten señalar, a partir de este relato de Moüette y de las ideas que transmite sobre la apostasía y la conversión, que los relatos de los trinitarios y mercedarios contribuyeron a reforzar la idea de que la apostasía era una consecuencia de la violencia ejercida por el musulmán, y que los apóstatas eran minoría. La exhibición del cautivo que ha demostrado su resistencia en la fe encuentra un escenario perfecto en las procesiones organizadas por los padres de la Merced en las ciudades que cruzan con los cautivos en su viaje de regreso a París. Así, en Marsella, una de las grandes ciudades de la Francia de la época, Bernard Bausset porta públicamente un cuadro para manifestar el socorro que Dios le había enviado. En Le Castellet, en la Provenza, Bausset lleva este cuadro a la capilla de Santa Ana, en la que permanecerá en depósito y que él ofrenda como acción de gracias ${ }^{81}$. Estas escenificaciones no sólo sirven para demostrar que se ha conservado un fiel, sino también un súbdito del reino, que ha preferido seguir sirviendo al rey de Francia que al sultán de Marruecos.

\section{LA INSTRUMENTALIZACIÓN RELIGIOSA Y POLÍTICA DE LA MEMORIA TRAUMÁTICA DEL CAUTIVO}

Germain Moüette es un personaje histórico, real, y su Relation de captivité contiene información relevante y fidedigna sobre el Marruecos del siglo XVII, pero no todo lo que narra el autor está exento de materia literaria. La obra de Moüette, como la de muchos otros cautivos europeos, colabora en la construcción de un arquetipo que se multiplicará como modelo literario en los siglos XVIII, XIX y XX: el cautivo cristiano sometido a la prueba de la apostasía del Cristianismo y la conversión al Islam por parte de la más alta autoridad del reino musulmán, el sultán, o por su comprador/ dueño. En este epígrafe final queremos recapitular algunos datos y aportar algunas reflexiones sobre este particular ¿Es probable que Germain Moüette no sea el autor de esta Relación? ¿Es posible que la autoría le corresponda a los religiosos de la Orden de la Merced? ¿Cuál es el proceso de elaboración de su texto autobiográfico?

Los cautivos solían pasar bastante tiempo con los religiosos a su vuelta de Berbería, no sólo durante el viaje de retorno, sino durante un período de tiempo variable antes de regresar a sus hogares. En este período de tiempo tenían lugar las procesiones y las acciones de gracias. En el caso de Moüette, el viaje de vuelta tuvo lugar en 1681.

\footnotetext{
78 Norton, op. cit. (nota 44), p. 262.

79 Bunes Ibarra, M. Á. de: "Reflexiones sobre la conversión al Islam de los renegados en los siglos XVI y XVII", Hispania Sacra, 42 (1990), p. 185.

80 Ibidem, p. 193.

81 MoüetTe, op. cit. (nota 5), p. 157.
} 
Los Padres de la Merced y los cautivos redimidos partieron de Mequinez el día 25 de febrero de 1681, dejaron Tetuán el día 13 de mayo, y llegaron a Marsella, a dónde habían viajado vía Málaga, el día 26 del mismo mes. De Marsella fueron a Toulon, pasando por La Ciotat. De Toulon a Aix, pasando por La Sainte Baume. Moüette dejó la procesión en Aix-en-Provence, y de allí partió a caballo hasta Avignon, ciudad en la que se embarcó por el Ródano. En su relato, Moüette menciona numerosas localidades francesas por las que pasaron los cautivos y en las que se celebraron procesiones: Lyon, Mâcon (Mâçon en el original), Chalon sur Saône (Châlons sur Saone), Arnayle-Doc (Arle-Duc), Saulieu (Solieux), Avallon (Avalon), Chablis, Auxerre, Joigny y Sens. Finalmente, el 19 de julio, llegaron a París, visitando allí lugares como NotreDame, y finalmente, Versalles. Los redentores de la Merced habían partido hacia Mequinez en 1680. Moüette dice haber participado en las negociaciones con los alcaides y con el sultán para la llegada de los mercedarios a la ciudad. Los redentores son Bernard Monel, de la congregación de París, y Bernard Mege y Joseph Castel, de la provincia de Tolose (Toulouse) ${ }^{82}$. Moüette tuvo relación con varios de los religiosos: por un lado, el padre Monel le comunica que el abad de Chartres le había encomendado encarecidamente que le rescatara; por otro lado, el padre Mege había oficiado una misa en la prisión y les había administrado los sacramentos a los cautivos. Igualmente, el padre Cartier, que había recibido a los cautivos y sus redentores en Marsella, les había conducido hacia París, y le había prestado a Moüette un caballo para ir a Avignon. En el caso de Cartier, Moüette expresa su admiración por él repetidamente, e incluye unas notas biográficas sobre su vida pasada y sus actividades religiosas. Moüette señala que los cautivos fueron trasladados a España en una embarcación de un tal Sieur Boyer, un mercader francés, procedente de Cassis (Provenza), instalado en Tetuán ${ }^{83}$. Este mercader es uno de los testigos que dan fe del martirio de Bernard Bausset. Boyer fue expulsado de Marruecos por unas diferencias que tuvo con el gobernador de Alcazarquivir y con el de Tetuán a causa de la misión de redención de los mercedarios, y, según dice Moüette, él le pidió que escribiera sus memorias sobre su vida y su redención, para enviárselas a sus correspondientes en Marsella. Es bastante significativo que tras confesar esta petición de Boyer, acto seguido Germain Moüette añada: "ce que je fis volontiers" ("cosa que hice de buena gana") ${ }^{84}$.

Guy Turbet-Delof ha señalado varias cuestiones de interés sobre la autoría de los textos de Moüette. En realidad, el cautivo tuvo que disputarle la autoría de sus textos a tres autores, Louis Desmay, P. Calault de Villalain y Barthélémy Gauthier ${ }^{85}$. En 1680, el 25 de diciembre, Moüette le había entregado uno de sus manuscritos a Barthélémy Gauthier, hermano del cónsul de Saléer, casi con toda seguridad su Historia de las conquistas de Moulay Rachid. Gauthier habría intentado apropiarse la autoría de este texto. En octubre de 1681, P. Calault de Villalain, francés de Blois cautivo en

\footnotetext{
82 Ibidem, p. 145.

83 Ibidem, p. 156.

84 Ibidem, p. 154.

85 Turbet-Delof, op. cit. (nota 36), p. 276.

86 MoüetTe, op. cit. (nota 26), p. XXVII.
} 
Mequinez ${ }^{87}$, afirma haberle procurado a Moüette la materia para redactar su Relation, aún inédita ${ }^{88}$. En el prefacio de su Histoire des Conquestes de Mouley Archy, Moüette escribe lo siguiente sobre un tal Sieur Desmay (Louis Desmay), autor de una Relation nouvelle et particuliere du voyage des RR.PP de la Mercy aux royaumes de Fez et de Maroc, publicada en París un año antes que la Relation del propio Moüette ${ }^{89}$ :

J'ay ésté assez surpris dans la lecture de la petite Relation du voyage des RR.PP. de la Mercy, de sort que le Sieur Desmay qui l'a donnée au public avance que je luy ay fourny mes memoires afin de les publier un jour. Il est bien vrai que je les avois communiquer aux RR.PP de la Mercy, mais non pasa fin qu'il y mist rien de sa part, puisqu'ils estoient dans la même ordre que je les donne aujourd'huy ${ }^{90}$.

Lo que vemos en este breve resumen del devenir de sus textos es que los contenidos de los escritos de Moüette, al menos una parte, habían estado circulando en un período de tres años antes de la fecha de su publicación. En el transcurso de su largo viaje de regreso, Moüette también pudo haberle narrado sus peripecias a los frailes de la Merced, y éstos pudieron haber colaborado en la configuración de su Relation, un texto que en algunas de sus partes parece un producto culto de las memorias traumáticas de uno o de varios cautivos de los redimidos en la expedición de rescate a Marruecos. De hecho, Louis Desmay refiere haber redactado su Relation a petición del padre de Chilly, prior del convento de la Merced de París ${ }^{91}$. Habida cuenta que algún otro de los cautivos rescatados en esta expedición, P. Calault de Villalain, también redactó una memoria de su cautiverio ${ }^{92}$, es probable que estas obras reúnan experiencias compartidas por uno o más cautivos. Igualmente, la Relation de Moüette no es el único texto vinculado con una orden redentora en el que se publica la historia del cautivo en el foso de los leones de Mulay Ismail. Germain Moüette tampoco es el único escritor que habla de un "nouveau Daniel", ya que en la obra Voyage pour la redemption des captifs dans les royaumes d'Alger et de Tunis, de los mathurins (trinitarios) franceses François Comelin, Philemon de la Motte y Joseph Bernard (1721), también se habla de los "nouveaux Daniels" en referencia a los cautivos en Berbería, y se cuenta la historia de dos esclavos cristianos que fueron arrojados al foso de los leones ${ }^{93}$. Esta historia aparece en una suerte de opúsculo interno o suplemento titulado "La tradition de l'Église pour le rachat et le soulagement des captifs": significativamente, también menciona al sultán, la Ménagerie real y la presencia de una mujer española, y también subraya el hecho de que dos figuras religiosas musulmanas, en

87 Weiss, G.: Captives and corsairs: France and slavery in the Early Modern Mediterranean, Stanford University Press, 2011, p. 268, n. 89.

88 Turbet-DELOF, op. cit. (nota 36), p. 274.

89 Desmay, L.: Relation nouvelle et particuliere du voyage des RR.PP de la Mercy aux royaumes de Fez et de Maroc, París, Viuda de G. Clouzier, 1682.

90 MoüetTe, op. cit. (nota 26), p. XXXIV.

91 Desmay, op. cit. (nota 89).

92 Calault de Villalain, P.: Mémoire de Pierre Calault de Villalain d'octobre 1681, en De Castries, H. de: Les sources inédites de l'histoire du Maroc, 1, I, 1922, p. 582.

93 Comelin, F., De la Motte, P. y Bernard, J.: Voyage pour la redemption des captifs dans les royaumes d'Alger et de Tunis, París, Louis-Anne Sevestre, 1721, pp. 118-120. 
este caso marabouts ${ }^{94}$, fueron arrojados al foso y no fueron respetados por los leones. "La tradition de l'Église" había sido ya publicada en la obra de Jean Baptiste La Faye titulada État des royaumes de Barbarie (1703-1704) ${ }^{95}$, y la historia de los dos cautivos cristianos arrojados al foso de los leones también había aparecido ya en la Histoire du règne de Mouley Ismael publicada por Dominique Busnot en 171496: en la obra de Busnot, los arrojados al foso de los leones son dos cautivos ingleses a los que el sultán intenta convertir ${ }^{97}$. La misma historia había visto la luz en Amsterdam, en francés, en una obra de Jacques Bernard que sigue la estela de La Faye, la titulada Nouvelles de la Republique des Lettres ${ }^{98}$.

La ventura del leit motif del texto de Moüette a finales del siglo XVII y comienzos del siglo XVIII nos permite intuir que la potencia ideológica de ciertos relatos es la que ha hecho que se repitan a lo largo del tiempo, bien verbatim, o con algunas variaciones en detalles de la materia narrativa como el número de personajes, su procedencia, etc. En este caso, los arrojados al foso son dos esclavos cristianos y no uno; en algunos textos se dice que son "cristianos", en otros "franceses", y en otros "ingleses"; también las razones por las cuáles el sultán les ha hecho pasar por el tormento varían de versión a versión: ya sea para lograr su conversión al Islam, o únicamente para divertirse. La intermediaria sigue siendo una mujer española, y los sacrificados en el lugar de los cristianos, personajes de relevancia religiosa en el Islam. De nuevo los cautivos son equiparados con la figura del Daniel de la Biblia, son calificados como "mártires" y es calificada su gesta como un "milagro".

94 Un marabout es un hombre de especial piedad, "cercano a Dios". Se les ha denominado "santones".

95 La Faye, J. B.: État des royaumes de Barbarie, Tripoly, Tunis et Alger, Rouen, Guillaume Behourt, 1703, y La Haye, Meyndert, 1704.

96 Busnot, D.: Histoire du règne de Mouley Ismael, Rouen, Guillaume Behourt, 1714.

97 Ibidem, p. 218.

98 Bernard, J.: Nouvelles de la Republique des Lettres, Amsterdam, Desbordes et Pain, 1704, pp. 664-665. 